\title{
A validated Distributed Activation Energy Model (DAEM) to predict the chemical degradation of biomass as a function of hydrothermal treatment conditions
}

\author{
Julia P. Lancha ${ }^{a}$, Julien Colin ${ }^{a, b}$, Giana Almeida $^{c^{*}}$, Cédric Guerin ${ }^{a}$, Joel Casalinho ${ }^{b}$, Patrick Perré ${ }^{a, b}$ \\ a Université Paris-Saclay, CentraleSupélec, Laboratoire de Génie des Procédés et Matériaux, SFR \\ Condorcet FR CNRS 3417, Centre Européen de Biotechnologie et de Bioéconomie (CEBB), 51110 \\ Pomacle, France \\ ${ }^{b}$ Université Paris-Saclay, CentraleSupélec, Laboratoire de Génie des Procédés et Matériaux, 8-10 rue \\ Joliot-Curie, 91190 Gif-sur-Yvette, France \\ c Université Paris-Saclay, INRAE, AgroParisTech, UMR SayFood, 91300 Massy, France
}

Abstract:

This study proposes a DAEM (Distributed Activation Energy Model) approach to predict the chemical alterations of lignocellulosic biomass as a function of hydrothermal treatment conditions. The model is first tuned by an original device allowing the sample shrinkage to be continuously assessed during hydrothermal treatment in saturated water vapor up to $190^{\circ} \mathrm{C}$. The shrinkage dynamic is supplied in the DAEM model as an indicator of the degree of biomass conversion. A set of chemical analyses was performed at selected residence times and treatment temperatures to correlate this degree of conversion with the resulting chemical molecules. A set of functions was then derived from this database to correlate the degree of conversion with the components concentrations. Finally, a validation database was built with different combinations of temperature levels and residence times. The model was proved to be predictive on this new dataset.

Keywords: Lignocellulosic biomass; Steam explosion; Poplar; Shrinkage; Degradation kinetics

\footnotetext{
${ }^{*}$ Corresponding author:

Giana Almeida

giana.almeida@agroparistech.fr

1 avenue des Olympiades, 91300 Massy, France
} 


\section{Introduction}

The urgent need to reduce greenhouse gas emissions has reinforced the interest in the use of biomass for producing biofuels and chemicals. Compared to the first generation, secondgeneration biofuels ( $2 \mathrm{G}$ ) are more likely to diversify the raw material source by using lignocellulosic biomass, a broadly available and relatively low-cost feedstock (De Bhowmick et al., 2018).

However, the production of $2 \mathrm{G}$ biofuels and chemicals is more challenging than the first generation. Indeed, as lignocellulosic components play a role of support in plants, they are designed to withstand degradations, lasting for many decades in the case of trees. Their recalcitrant macromolecular structure is mainly composed of cellulose, hemicelluloses, and lignins, interlinked in a complex matrix. Consequently, the fragmentation of biomass into fermentable sugars requires a pretreatment to make carbohydrates sufficiently accessible for enzymatic hydrolysis. An extensive range of pretreatments is available, such as physical, chemical, mechanical, biological, and combined processes (Baruah et al., 2018; Mankar et al., 2021). Among them, steam explosion appears to be effective for many lignocellulosic biomasses, including softwood, hardwood, and agricultural residues (Baruah et al., 2018). It consists of two stages: (i) a hydrothermal treatment, in which the biomass particles are heated under saturated steam conditions; (ii) a rapid release of the pressure to atmospheric conditions (Haghighi Mood et al., 2013; Limayem and Ricke, 2012; Mihiretu et al., 2019). Pretreatment performance has a double effect on the economic profitability of the transformation chain due to its own significant cost and its impact on the yield of subsequent processes, namely enzymatic hydrolysis and fermentation. The mechanical properties of biomass at the end of the hydrothermal treatment are also of interest because they highly influence the efficiency of the explosion stage (Sui and Chen, 2016, 2015). Finally, the settings 
of the hydrothermal treatment can be adapted to produce molecules of interest such as furfural and 5-(hydroxymethyl)furfural. In order to monitor and optimize this pretreatment, the ultimate goal would be a model capable of predicting the kinetics of biomass alterations as a function of treatment conditions.

Previous studies have shown that chemical degradation can cause shrinkage in the case of wood heat treatment (Almeida et al., 2009). However, to the best of our knowledge, no study of shrinkage during hydrothermal treatment has been performed, probably due to the challenge of continuously measuring shrinkage with accuracy despite these severe conditions. As a matter of fact, in industry, the hydrothermal treatment is carried out between 160 and $270^{\circ} \mathrm{C}$ (Haghighi Mood et al., 2013), which implies a saturated steam pressure of up to 55 bar.

This study proposes shrinkage measured in situ as a continuous indicator of biomass alterations during hydrothermal treatment. A reaction chamber combined with rheological measurement was developed and further improved (Lancha et al., 2020; Mokdad et al., 2018) to perform continuous shrinkage measurements under conditions comparable to those used during the steam explosion. The originality of this device is its ability to perform continuous mechanical tests of biomass (various combinations of strain and stress) under water-saturated conditions of up to $190^{\circ} \mathrm{C}$. In the present work, this device was used to continuously assess the evolution of sample size during treatment (strain measurement at nearly zero-stress level).

By relating the alterations of chemical composition to continuous shrinkage measurements, thanks to a modeling approach, the objective of the present work is to propose a predictive tool. This tool will predict the concentration of main components produced by thermochemical degradation as a function of hydrothermal treatment conditions. This predictive model was achieved using the shrinkage evolution dynamics to indicate the degree of conversion that allowed for identifying the DAEM formulation parameters. Then, the first set of chemical 
analyses was used as a learning database to relay the degree of conversion with the production of chemical components. Finally, contrasted and different time-temperature pathways were used to build a second set of chemical analyses. This second set was used as a validation database to check the prediction ability of the model successfully. As a result, the model accounts for any time/temperature pathway up to nearly $200^{\circ} \mathrm{C}$.

\section{Materials and methods}

\subsection{Biomass and sampling}

The biomass used in this study comes from a 25-year poplar tree (Populus euro-americana 'Koster') that grew in a forest located in Auménancourt-le-Petit (Marne, North-East of France). Wood boards were cut, dried, and stored before sample preparation.

The control of plant material, sample preparation, sample characterization, and sample flow was crucial in achieving the objectives of this work. Samples were obtained from a single defect-free board with a straight grain angle. To minimize the biological variability of wood, samples were prepared along the longitudinal direction of wood (Figure 1). As it is well-known, wood properties vary along the radius (effect of growth conditions and age of tree over years) and along the tangential direction, given the possible gradient from normal wood to reaction wood. The sample size was chosen to fulfill the protocol's constraints: the amount of biomass required for chemical tests and sample size for shrinkage determination. These constraints impose sample sizes of $8 \times 8 \times 8 \mathrm{~mm}^{3}$ (radial - R, tangential - T, longitudinal - L) for shrinkage tests and $40 \times 8 \times 8 \mathrm{~mm}^{3}(\mathrm{R} \times \mathrm{T} \times \mathrm{L})$ for chemical tests. For the latter, the longitudinal direction was purposely chosen as the smallest dimension $(8 \mathrm{~mm})$ to ease mass transfer and thus ensure a good homogeneity of the hydrothermal treatment throughout the sample. The flow chart of all samples that allowed us to build the chemical databases together with the continuous 
assessment of shrinkage during hydrothermal treatment is depicted in Figure 1. All methods and protocols are briefly described hereafter.

The anhydrous mass of wood is indispensable to determine the mass loss due to the treatment. However, chemical analyses are not compatible with oven drying. The anhydrous mass was therefore obtained using pair samples exposed at the same conditions. The moisture content $X_{w}$ of both samples was considered equal and was determined on the discarded sample. It is classically determined by oven drying:

$$
X_{w}=\frac{m_{0}-m_{a}}{m_{a}}
$$

where $X_{w}$ is the moisture content of wood (dry basis), $m_{0}$ is the initial mass of the sample, and $m_{a}$ its anhydrous mass, as determined at $103^{\circ} \mathrm{C}$ until mass stabilization (Siau, 1984).

Before hydrothermal treatment, the samples were saturated with water. This saturation was performed for two main reasons: (i) to ensure a good heat transfer; (ii) to avoid hydric swelling at the beginning of the test, which would disturb the shrinkage measurements. To achieve saturation, samples were immersed in distilled water and subjected to vacuum cycles. For this study, no acid was added to water.

\subsection{Hydrothermal treatment}

The hydrothermal treatment was performed in a device conceived by our team (Figure 2) and presented in detail elsewhere (Lancha et al., 2020; Mokdad et al., 2018). It consists of two chambers. The bottom one (Figure $2 \mathrm{~b}$ ) is where the treatment takes place and can reach up to $190{ }^{\circ} \mathrm{C}$ at saturated water vapor pressure (higher than 13 bars). The top one (Figure 2a) houses the instrumentation and is kept at ambient conditions - typically $30^{\circ} \mathrm{C}$ and $50 \%$ relative humidity $(\mathrm{RH})$ - to preserve the electronic components. A patented system that involves a 
controlled leak (Placet and Perré, 2006) allows such contrasted conditions to be maintained in the connected chambers (Figure 2.3). The successive fins (Figure 2.1) and the controlled leakage (Figure 2.2) ensure a downwards convective flux of dry and cold air that progressively limits and eventually stops the upwards convective-diffusion vapor flux. An RH/temperature sensor is installed in the upper chamber to check if the air leakage is enough to ensure moderate conditions despite the severe conditions imposed in the lower chamber.

The rheological instrumentation includes three main parts: an actuator (Figure 2c-NEWPORT LTA-HL, $25 \mathrm{~mm}$ travel range, $120 \mathrm{~N}$ load capacity, $50 \mathrm{~nm}$ minimal increment), a charge rod (Figure 2f), and a load cell (Figure 2d - MEASUREMENT SPECIALTIES XFTC 310, full range of $100 \mathrm{~N})$.

The temperature was measured by a K-thermocouple near the sample and controlled by a PID system (EUROTHERM 3216). The vapor saturated atmosphere surrounding the sample ensures a good heat transfer inside the chamber while avoiding drying-induced shrinkage. Tests were performed at $150,160,170,180$, and $190^{\circ} \mathrm{C}$ to produce two complementary datasets: the learning database and the validation database. In the mechanical test configuration, the device allows the study of one sample at a time, with maximum dimensions of $8 \times 8 \times 8 \mathrm{~mm}^{3}$. For sample treatment intended for chemical analyses, up to 3 samples of $8 \times 8 \times 40 \mathrm{~mm}^{3}$ are placed in the bottom chamber.

The experimental protocol reads as follows:

1. Heating from room temperature at ca. $8^{\circ} \mathrm{C} / \mathrm{min}$;

2. Plateau at $100^{\circ} \mathrm{C}$ for one hour;

3. Cooling to room temperature at ca. $9^{\circ} \mathrm{C} / \mathrm{min}$ thanks to external fans;

4. A plateau at room temperature for 90 minutes.

5. Heating to the treatment temperature at ca. $8^{\circ} \mathrm{C} / \mathrm{min}$; 
6. Maintaining this for 40 minutes;

7. Cooling to room temperature.

After treatment, samples were weighed to determine the mass loss (ML) due to hydrothermal treatment as follows:

$$
M L(\%)=\frac{m_{n}-m_{t}}{m_{n}} .100
$$

Where, $m_{n}$ and $m_{t}$ are the anhydrous mass of native and treated biomass, respectively. The anhydrous masses were obtained as described in the previous section.

\subsection{Shrinkage determination}

In the present work, the rheological system was used to assess the sample shrinkage during hydrothermal treatment. This assessment is performed by measuring the rod displacement at quasi-zero force. The following protocol was developed:

1. Slow displacement of the rod towards the sample $(0.005 \mathrm{~mm} / \mathrm{s})$;

2. Contact detection thanks to a force threshold;

3. Backward translation to release the contact with the sample.

Limiting the force applied by the charge rod to the sample is indeed required to avoid any deformation due to viscoelastic behavior. Two precautions achieved a very low detection level of $0.05 \mathrm{~N}$ :

- The force value is obtained by a median filter applied on-line on a sliding window of 200 measurements acquired at a frequency of 300 measurements per second;

- $\quad$ The load cell drift was continuously assessed after upwards translation.

This protocol was repeated every 90 seconds during treatment. The size of the sample was obtained when the position of the actuator satisfied the contact criterion. The results were 
corrected with a blank test, accounting for the thermal dilatation of the device. The sample dimensions were also verified before and after treatment, outside the chamber, using a laser sensor (BULLIER AUTOMATION M5L/4).

Preliminary tests highlighted the role of a first plateau $\left(100^{\circ} \mathrm{C}, 1 \mathrm{~h}\right)$ before the hydrothermal treatment for accurate shrinkage measurement. Indeed, under water-saturated conditions, wood is subjected to the hygrothermal recovery of the delayed strain of growth stress in the range $80^{\circ} \mathrm{C}$ to $100^{\circ} \mathrm{C}$ (Gril et al., 1993; Salmén, 1990; Sujan et al., 2015; Ueda Matsuo et al., 2016). After 1 hour at $100^{\circ} \mathrm{C}$, hygrothermal recovery is complete (Jullien, 1995) with negligible chemical degradation (Liu et al., 2013; Vallejos et al., 2017).

The raw shrinkage $\left(S_{\text {raw }}\right)$ was then calculated as a percentage of the length at room temperature using the formula:

$$
S_{\text {raw }}(\mathrm{t})=\frac{L_{0}-L_{t}}{L_{0}}
$$

where $L_{o}$ is the sample length at room temperature, after blank correction and hygrothermal recovery correction, and $L_{t}$ its dimension at time $t$.

Finally, a last correction is needed to obtain a shrinkage value induced only by the treatment (the irreversible part of shrinkage). Indeed, as the fiber saturation point (FSP) decreases with temperature (Siau, 1984), the amount of bound water at saturation also decreases with temperature. This effect is reversible and should not be included in the treatment-induced shrinkage. The correction was done based on the dimension variation measured between the end of the plateau at $100^{\circ} \mathrm{C}-$ when hygrothermal recovery is already relaxed - and a plateau at room temperature for 90 minutes preceding the treatment plateau. The temperatureinduced shrinkage $S_{T}$ is assumed to be linear with temperature. Thus, we finally obtain the treatment shrinkage $S_{\text {treatment }}$ as: 


$$
\mathrm{S}_{\text {treatment }}(\mathrm{t})=\mathrm{S}_{\text {raw }}(\mathrm{t})-\mathrm{S}_{\mathrm{T}}(\mathrm{T}(\mathrm{t}))
$$

In this study, the shrinkage of wood was monitored in the radial direction.

\subsection{Chemical analysis}

Offline chemical analyses were performed to assess the biomass alteration due to hydrothermal treatment (Figure 1). Unless otherwise specified, chemical analysis followed National Renewable Energy Laboratory's (NREL) analytical procedures (Sluiter et al., 2011, $2008 \mathrm{~b}, 2008 \mathrm{a})$. The total process requires $5 \mathrm{~g}$ of biomass.

As shown in Figure 1, two fractions originate from hydrothermal treatment: the treated biomass (\#3 - solid fraction) and the treatment solution (\#9 - liquid fraction). Native and treated biomasses (fractions \#1 and \#3) were ground prior to chemical analysis. This grinding was performed with a cryogenic ball mill (RETSCH CryoMill supplied with liquid nitrogen) to avoid any heat releases and thus any additional chemical degradation. Then, an aliquot of native and pretreated biomass (fractions in red in Figure 1) was analyzed for isotherm sorption. The remaining powder went through extraction processes. The extractives and the treatment liquid (fractions in blue in Figure 1) were quantified for monosaccharides, oligosaccharides, organic acids, degradation products, and $\mathrm{pH}$.

The treatment intensity was evaluated by dosing the liquid fraction, which contains hydrolyzed and partially degraded biomass components.

\subsubsection{Water and ethanol extractions}

Native biomass was submitted to Soxhlet water and ethanol extractions according to NREL's protocol. However, for the treated biomass, an adaptation of the NREL method was necessary as the sample is not directly in contact with the hydrothermal process liquid (\#9 in Figure 1). Consequently, the treated sample (\#3 in Figure 1 ) may have significant quantities of 
hydrolyzed components - attached to its surface or in the liquid phase of internal pores. Instead of just washing the treated biomass, as proposed by the NREL method, a supplementary extraction was performed, and the extracted components were included in the final result. To prevent any additional thermal degradation of chemical compounds, a threestep cold extraction was chosen. Distilled water was put in contact with an aliquot of the solid sample in a 20:1 (m/m) ratio. The mixture was submitted to an ultrasound bath for five minutes and then separated with a centrifuge. The supernatant was collected, and the pellet was submitted to two additional extractions following the same protocol.

\subsubsection{Chemical quantification}

Monosaccharides and organic acids

Fractions presented in blue in Figure 1 were analyzed for monosaccharides and organic acids. Quantification was carried out on an Ultima 3000 HPLC (THERMO FISHER SCIENTIFIC) coupled with a Refractive Index Detector RI-101 (SHODEX). Separation was achieved on an Aminex HPX-87H column $(300 \times 7.8 \mathrm{~mm})$ from Biorad at a temperature of $30^{\circ} \mathrm{C}$. A mobile phase of $2 \mathrm{mM}$ of sulfuric acid (VWR) at a flow rate of $0.5 \mathrm{~mL} / \mathrm{min}$ was used in isocratic mode, and the injection volume was $10 \mu \mathrm{L}$. The total run analysis was 30 minutes. Components were identified by comparison of their retention time with standard solutions of glucose (ACROS ORGANICS), xylose (SIGMA-ALDRICH), arabinose (ACROS ORGANICS), and acetic acid (FISHER CHEMICAL). Quantification was achieved using the area of the peak in external calibration. The range of concentration was from 0.2 to $10 \mathrm{~g} / \mathrm{L}$.

\section{Degradation products}

In the same fractions, quantification of furfural and 5-(hydroxymethyl)furfural (HMF) were carried out on an Ultima 3000 HPLC (THERMO FISHER SCIENTIFIC) coupled with an UV Detector. Separation was achieved on an Acclaim Polar Advantage $/$ C $C_{18}$ column $(4.6 \times 150 \mathrm{~mm}$, 
$3 \mu \mathrm{m}, 120 \AA$ ) from THERMO FISHER SCIENTIFIC. The column temperature was maintained at $30{ }^{\circ} \mathrm{C}$. The mobile phase was a mixture of two solvents. Solvent A: Milli-Q water; and solvent $\mathrm{B}$ : Acetonitrile (SIGMA-ALDRICH) at a $0.3 \mathrm{~mL} / \mathrm{min}$ flow rate. Elution was achieved in gradient mode with an initial composition of $80 \%$ of $A$ and $20 \%$ of $B$, held for 5 minutes. The proportion of B was then gradually increased to $99 \%$ in 10 minutes and held at $99 \%$ for 5 minutes, followed by going back to the initial composition and stabilization of the column for 10 more minutes, summing a total run analysis of 30 minutes. The injection volume was $5 \mu \mathrm{L}$. Degradation products were identified by comparing their retention time and their UV spectra with standard solutions of HMF (SIGMA-ALDRICH) and furfural (SIGMA-ALDRICH). UV spectra were recorded from 200 to $380 \mathrm{~nm}$, quantification of HMF and furfural was done from absorbance at 277.8 and $285.5 \mathrm{~nm}$, respectively, which corresponds to their maximum absorption. Quantification was achieved using the area of the peaks in external calibration, within the range of 0.1 to $30 \mathrm{mg} / \mathrm{L}$.

Oligosaccharides (OS)

OS concentrations were determined in the liquid fractions represented in blue in the flow chart (Figure 1) from the difference of monomeric sugars concentrations measured before and after an analytical hydrolysis step (Sluiter et al., 2008a). To perform this analytical hydrolysis, each liquid fraction is mixed with $72 \% \mathrm{H}_{2} \mathrm{SO}_{4}$ to obtain an acid concentration of $4 \%$ and then autoclaved at $121^{\circ} \mathrm{C}$ for 1 hour.

\subsubsection{Sorption measurements}

The isotherms of ground native and treated biomass (fractions represented in red in Figure 1) were obtained by Dynamic Vapor Sorption (DVS Intrinsic from SURFACE MEASUREMENT SYSTEMS). Approximately $20 \mathrm{mg}$ of ground biomass were put in the sample pan. A constant flow of nitrogen is mixed to water vapor to ensure the desired $\mathrm{RH}$ (accuracy of $0.5 \%$ ) at a 
temperature of $25^{\circ} \mathrm{C}$ (accuracy of $0.1^{\circ} \mathrm{C}$ ). The adsorption/desorption cycle ranged from 0 to $90 \%$ and back to $0 \%$ by steps of $10 \%$. Samples were kept at a constant RH level until the mass change per minute ( $\mathrm{dm} / \mathrm{dt}$ ) reached $0.002 \%$, as recommended in literature (Hill et al., 2009). The measurements were repeated in duplicate.

\subsection{Distributed activation energy model (DAEM)}

Due to its complex ultra-structure and heterogeneous macromolecular composition, lignocellulosic biomass decomposes at different rates when subjected to a thermochemical treatment through different mechanisms and pathways. Thus, describing the process over a large range of conditions using a discrete set of reactions presents certain challenges. In order to face such complex decomposition, the concept of activation energy distribution was initially proposed by Vand (Vand, 1943) and further applied to the decomposition of coal (Anthony and Howard, 1976; Pitt, 1962).

Since then, the DAEM approach has been extensively used to model the thermal degradation of lignocellulosic biomass subjected to pyrolysis (Cai et al., 2014; Cai and Liu, 2008; Cavagnol et al., 2015; Lin et al., 2018; Perré et al., 2021). The accuracy of this method when dealing with lignocellulosic biomass, namely its prediction ability compared to multi-step reactions (Tian and Perré, 2021), encouraged us to use DAEM to model the kinetics of degradation during hydrothermal treatment. To the best of our knowledge, such a model has never been used for the hydrothermal treatment of lignocellulosic biomass.

The model assumes that the decomposition mechanisms follow multiple parallel first-order reactions with different activation energies, represented by a continuous distribution function (Cai et al., 2014; Perré et al., 2021). Each independent and irreversible reaction $i$ contributes to the hydrolyzed mass fraction according to the following equation: 


$$
\frac{d\left(\frac{V_{i}}{V_{i}^{\infty}}\right)}{d t}=k_{i}\left(\frac{V_{i}^{\infty}-V_{i}}{V_{i}^{\infty}}\right)=A \exp \left(-\frac{E_{i}}{R T(t)}\right)\left(\frac{V_{i}^{\infty}-V_{i}}{V_{i}^{\infty}}\right)
$$

where $V_{i}$ is the hydrolyzed mass fraction of the reaction $i, V_{i}{ }^{\infty}$ the total mass fraction that can be hydrolyzed, $A$ the pre-exponential factor (assumed constant for all reactions), $E_{i}$ the activation energy, $R$ the universal gas constant, $T$ the temperature, and $t$ the time.

Considering the complexity of the reactions involved in the degradation of lignocellulosic biomass, a continuous distribution $f(E)$ of activation energies is assumed, representing the fraction released by reactions with activation energy inferior to $E$. The derivative of this function with respect to the activation energy gives a distribution function of the product fraction concerned by each activation energy:

$$
d V^{\infty}=V^{\infty} f(E) d E
$$

From Equations (5) and (6), we obtain:

$$
\alpha=\frac{V}{V^{\infty}}=1-\int_{0}^{\infty} \exp \left[-\int_{t_{0}}^{t} A \exp \left(-\frac{E}{R T}\right) d t\right] f(E) d E
$$

where $\alpha$ is the degree of conversion, ranging between 0 and 1 .

In the absence of additional information, a Gaussian, hence symmetrical, distribution is often chosen as a distribution function (Cai et al., 2014). It involves two parameters, the mean activation energy $E_{0}$ and the standard deviation of the energy distribution $\sigma$ : 


$$
f(E)=\frac{1}{\sigma \sqrt{2 \pi}} \exp \left[-\frac{\left(E-E_{0}\right)^{2}}{2 \sigma^{2}}\right]
$$

For modeling purposes, this distribution was discretized into a finite set of $\mathrm{N}$ parallel reactions.

Finally, the shrinkage $(S)$ is considered to be a macroscopic indicator of the degree of conversion and is assumed to depend linearly on $\alpha$ :

$$
S(\%)=\beta \cdot \alpha
$$

To relate the mass fraction of a chemical compound $j\left(X_{j}\right)$ to the degree of conversion $\alpha$, simple expressions $\left(X_{j}=g(\alpha)\right)$ were derived to match the trends of the chemical analyses.

Two different datasets were used for model calibration and validation. The chemical analyses of the learning database were performed after hydrothermal treatments at two temperature levels -160 and $180{ }^{\circ} \mathrm{C}-$ and at four treatment durations $-0,10,20$, and 40 minutes. It is important to underline that the so-called 0-min treatment means that the chamber was heated to the treatment temperature and then immediately cooled down. For the validation database, other conditions were chosen from the continuous evolution of shrinkage to obtain different theoretical values of $\alpha$ with different temperature/residence time combinations:

- For $\alpha=0.6: 150{ }^{\circ} \mathrm{C}, 75 \mathrm{~min} ; 160^{\circ} \mathrm{C}, 38 \mathrm{~min}$; and $170^{\circ} \mathrm{C}, 19 \mathrm{~min}$;

- For $\alpha=0.8: 160^{\circ} \mathrm{C}, 93 \mathrm{~min} ; 170^{\circ} \mathrm{C}, 47 \mathrm{~min}$; and $190^{\circ} \mathrm{C}, 13 \mathrm{~min}$;

- For $\alpha=0.9: 170^{\circ} \mathrm{C}, 89 \mathrm{~min}$.

\section{Results and discussion}

\subsection{Shrinkage kinetics}

Typical shrinkage results at 160 and $180^{\circ} \mathrm{C}$ in the radial direction are presented in Figure 3 . At least two repetitions were performed for each condition, and similar results were obtained. Thanks to the corrections explained in section 2, the values plotted in Figure 3 are the 
irreversible part of the shrinkage ( $S_{\text {treatment }}$ of equation 2$)$, which is directly tied to the hydrothermal treatment. As already identified for pyrolysis (Almeida et al., 2009), shrinkage depicts a monotonic increase with the severity of the treatment.

It is well known that hemicellulose is the first lignocellulosic component degraded during hydrothermal treatment (Garrote et al., 1999; Ximenes et al., 2017). Some lignin degradation could also occur and partly explain the dimensional changes of poplar since hardwood lignins are rich in syringil units, the most susceptible to hydrothermal degradation (Wang et al., 2017). In addition to hydrolysis, a rearrangement in the lignocellulosic matrix organization can also be at the origin of shrinkage. Previous works (Donohoe et al., 2008; Lancha et al., 2021) have indeed shown that, once the lignin reaches its glass transition temperature, it becomes fluid and coalesces, being later forced out of the matrix by the collapse of microfibrils.

Further analyses of the chemical degradations of biomass that may induce shrinkage are presented in the following sections. These chemical analyses are performed on samples after specific treatments, characterized by various combinations of temperature levels and residence times, as explained at the end of section 3 .

\subsection{Mass loss}

Mass loss (ML) is widely used as a macroscopic indicator of biomass degradation and treatment intensity (Almeida et al., 2010; Pachón-Morales et al., 2019). Figure 4a presents the average $\mathrm{ML}$ for the two treatment temperatures $\left(160^{\circ} \mathrm{C}\right.$ and $\left.180^{\circ} \mathrm{C}\right)$ applied for the learning database.

As expected, ML increases with both the treatment temperature and the residence time. After 40 minutes of treatment at $180^{\circ} \mathrm{C}, \mathrm{ML}$ is twice as high as at 20 minutes, reaching $27.3 \%$. Whereas after 40 minutes at $160{ }^{\circ} \mathrm{C}$, only $11.5 \%$ of $\mathrm{ML}$ is observed. It is noted that, as the 
heating-up phase takes a few minutes, the equivalent treatment time at the beginning of the plateau is around 10 minutes. This is why biomass degradation is already observed at 0 minutes $\left(1.02 \%\right.$ and $7.49 \%$ respectively for the tests at $160^{\circ} \mathrm{C}$ and $\left.180{ }^{\circ} \mathrm{C}\right)$.

These results are consistent with shrinkage measurements and suggest that more severe treatments cause a higher biomass degradation. They also agree with previous studies. For example, a mass loss of $30.2 \%$ was found for Eucalyptus globulus biomass subjected to hydrothermal treatment at $180^{\circ} \mathrm{C}$ for 45 minutes (Vila et al., 2013). Assor et al. (Assor et al., 2009) reported basic density losses in oak and spruce subjected to hydrothermal treatment equivalent to the mass loss experienced by the samples. They attributed those losses to the hydrolysis and the dissolution of cell wall polymers.

\subsection{Sorption isotherms}

The alteration of the cell wall was also assessed by the change of sorption isotherms compared to the native biomass (Figure 4b). Biomass submitted to $100^{\circ} \mathrm{C}$ for 1 hour exhibits little change. This observation validates the method used for the hygrothermal recovery of growth stress, which assumed the absence of irreversible chemical effects during this plateau at $100{ }^{\circ} \mathrm{C}$.

The impact of the hydrothermal treatment on biomass hygroscopicity is clearly observed by the global decrease of the equilibrium moisture content (EMC) with the increase of treatment severity. At $50 \%$ of RH during adsorption, the difference between native biomass and the treatment at $180^{\circ} \mathrm{C}$ for 40 minutes is $1.76 \%$. This value represents a relative decrease of EMC by $24.3 \%$. These facts have already been reported in the literature for both hydrothermally treated wood (Yin et al., 2011) and torrefied wood (Almeida et al., 2009; Phuong et al., 2007) and were attributed to the reduction of accessible hydroxyl groups (Engelund et al., 2013; Phuong et al., 2007). In the case of hydrothermal treatment, this reduction can be explained by 
a loss of the functional hydroxyl group itself, of acetyl groups or of entire osidic monomers, which is well illustrated by the increasing concentration of acetic acid in the liquid fraction (Figure $4 d$ ) and the loss of $\mathrm{C} 5$ units (Figure 5a-b), presented in the next sections. The loss of $\mathrm{OH}$ groups reduce the ability of biomass to bind water. Bound water between microfibrils forces them apart, increasing the cell wall volume (Engelund et al., 2013). The significant reduction in water-adsorption capacity results in a reduction of the volume, which is consistent with the evolution of shrinkage presented in Figure 3.

\subsection{Chemical degradation}

Figure $4 \mathrm{c}$ and $\mathrm{d}$ present, respectively, the $\mathrm{pH}$ and the mass of acetic acid in the liquid fraction (sum of fractions \#9 and \#10 in Figure 1) released during treatment. In this work, only distilled water was used as hydrothermal process liquid. Nevertheless, it is possible to observe a decrease in $\mathrm{pH}$ during the treatment, from 4.96 and 4.08 at the beginning of treatment plateau (0 minute) to 3.74 and 3.33 after 40 minutes, for 160 and $180{ }^{\circ} \mathrm{C}$, respectively. The formation of acetic acid mainly explains this decrease: up to 0.31 and 1.32 grams of acetic acid per gram of native biomass (for $160^{\circ} \mathrm{C}$ and $180^{\circ} \mathrm{C}$, respectively) are formed and released in the liquid fraction. This is due to the hydrolysis of hemicellulose O-acetyl branching groups in the presence of hydronium ions from water autoionization. Acetic acid then acts as an autocatalysis agent itself, promoting hydrolysis (Garrote et al., 1999; Ximenes et al., 2017). Thus, deacetylation represents an important fraction of the mass loss. For mild treatment conditions, this phenomenon is mainly visualized by a decrease in $\mathrm{pH}$ rather than an increase in the acetic acid concentration because its values probably range under the quantification limit of the HPLC-RI method applied $(0.2 \mathrm{~g} / \mathrm{L})$. 
Figure 5 presents the effect of time and temperature on the composition of the liquid fraction in terms of $\mathrm{C} 5$ and $\mathrm{C} 6$ sugars and their respective degradation products - furfural and HMF.

Once again, results for fractions \#9 (exhausted treatment liquid) and \#10 (water and extractives) (Figure 1) are merged.

These results provide a synthetic overview of the hydrolysis reactions that take place during hydrothermal treatment. The oligosaccharide levels result from the balance between their production by polysaccharides degradation and their consumption by hydrolysis into monosaccharides. In milder treatments, production exceeds consumption, increasing the content of $\mathrm{C} 5$ and $\mathrm{C} 6 \mathrm{OS}$. For a treatment temperature of $160^{\circ} \mathrm{C}$, OS represent from $2.5 \%(0$ minutes) to $30.9 \%$ (40 minutes) of the $\mathrm{C} 5$ polysaccharides initially present in native biomass $(\mathrm{m} / \mathrm{m})$ and from $0.2 \%$ (0 minutes) to $0.5 \%$ (40 minutes) for $\mathrm{C} 6$ sugars. At $180{ }^{\circ} \mathrm{C}$ these values range from $8.1 \%$, at the beginning of the treatment plateau, up to a maximum of $51.5 \%$ after 20 minutes for $\mathrm{C} 5$ sugars and from $0.3 \%$ to around $0.9 \%$ for $\mathrm{C} 6$ sugars. Between 20 and 40 minutes at $180^{\circ} \mathrm{C}$, the oligosaccharide content decreases due to the reduction in the solid matrix available for hydrolysis, as stated by the mass loss values. Likewise, the monosaccharide content is a compromise between its production by hydrolysis and its degradation into smaller products such as furfural (for C5 sugars) and HMF (for C6 sugars). Unlike OS, however, monosaccharides' content increases steadily. This indicates that, for the studied conditions, monosaccharide production is still higher than its degradation.

Total hydrolysis of up to $62.1 \%$ of $\mathrm{C} 5$ polysaccharides is observed after 20 minutes at $180{ }^{\circ} \mathrm{C}$. However, the total amount of recovered C5 sugars (and their degradation products) decreases after 40 minutes at the same temperature. It is probably due to the severity of the treatment, which may cause further degradation of furfural into smaller degradation products or the condensation of $\mathrm{C} 5$ and/or furfural with lignin forming insoluble products (Hu et al., 2012; 
Shinde et al., 2018). From this perspective, the concentration of hydrolysis products measured for more severe conditions may be under-estimated. This trend is not observed for the mildest treatment $\left(160^{\circ} \mathrm{C}\right)$.

C5 sugars are much more hydrolyzed than $\mathrm{C} 6$ sugars. While the total amount of $\mathrm{C} 5$ (and its degradation products) present in the liquid fraction reaches $62.1 \%$ at $180{ }^{\circ} \mathrm{C}$ after 20 minutes, no more than $1.2 \%$ of $\mathrm{C} 6$ are fractionated (percentage of the total amount in the raw biomass). These results confirm the trends available in published works (Li et al., 2014; Liu et al., 2012; Nitsos et al., 2013). This difference is attributed to the crystallinity of cellulose (Li et al., 2014) - only composed of C6 - and the lower degree of polymerization (Liu et al., 2012) of hemicelluloses - mainly composed of C5 in poplar.

Polymeric matrix hydrolysis follows the same trend as shrinkage. For the treatment severities studied here, shrinkage seems to be mainly tied to a loss of cell wall thickness, and its effect on cellular deformation, due to the degradation of hemicellulose polymers into nonstructural components (Lancha et al., 2021). This hypothesis is also consistent with the decrease in hygroscopicity, as the - $\mathrm{OH}$ groups available for water adsorption belong mainly to hemicellulose.

More generally, the mass loss induced by the hydrolysis of the polymeric matrix weakens the cell wall structure. It leads to significant ultrastructural and anatomical changes, evidenced by shrinkage at the macroscopic level. 


\subsection{The degree of conversion $(\alpha)$ as an indicator of chemical changes}

\subsubsection{Model calibration}

The parameters of a DAEM model were identified using the two tests simultaneously $\left(160^{\circ} \mathrm{C}\right.$ and $180^{\circ} \mathrm{C}$ ). The identified parameters based on radial shrinkage are $A=1.20 \times 10^{18} \mathrm{~min}^{-1} ; E_{0}=$ $2.66 \mathrm{~J} / \mathrm{mol} ; \sigma=6.15 \times 10^{3} \mathrm{~J} / \mathrm{mol} ; \beta=1.392$. The curves simulated with the identified parameters are plotted in Figure 3.

Values of activation energy of the same order of magnitude were found for eucalyptus during hydrothermal treatment (Vila et al., 2013). Previous works have applied DAEM to the pyrolysis of components of lignocellulosic biomass separately (Cai et al., 2014). These works found that standard deviation $(\sigma)$ increases with the degree of heterogeneity of the component, being higher for lignin, followed by hemicellulose and finally cellulose (divided by a factor of 10 each time). The standard deviation of the Gaussian distribution found in this study is between the ones attributed to lignin and hemicellulose in other studies (Cai et al., 2014). Given the high heterogeneity of these components, they should be responsible for the wide activation energy distribution.

Results from chemical quantification - performed in triplicate, with their respective standard deviation - and the degree of conversion $(\alpha)$ calculated from the DAEM model for each temperature and duration tested are summarized in supplementary material.

Using the learning database, the physical and chemical characterizations of biomass were plotted as a function of the degree of conversion $\alpha$ (Figure 6). For that purpose, the values of the degree of conversion were calculated using the DAEM model with the fitted parameters. As this model can consider any time-temperature pathway, the treatment occurring before the plateau is included by default. Consistently, the degree of conversion is higher than zero at the 
beginning of the plateau. As a very interesting result, a master curve emerges as both temperature levels are located on the same trajectory. The presence of this master curve proves that shrinkage is a good indicator of the chemical degradation of biomass over the studied range of temperature levels and for a wide range of residence times. The sole visible deviation is the mass loss, for which values measured after 10 and 20 minutes at $180^{\circ} \mathrm{C}$ are smaller than the general trend.

As the degree of conversion, calculated by the DEAM model and fitted from the in situ shrinkage measurement, can be seen as a synthetic indicator of chemical alterations, simple expressions were derived to relate chemical measurements to the degree of conversion (Table 1). These expressions are also plotted in Figure 6.

\subsubsection{Model validation}

In this paragraph, the validation database was used to check the potential of the DAEM model to predict the kinetics of biomass degradation during hydrothermal treatment. This validation step is straightforward: the expression tuned from the learning database (Table 1) was used to predict the analyses performed on samples treated under completely different temperature levels and residence time combinations. As previously described, seven additional experimental combinations were performed and analyzed (square markers in Figure 6). For consistency, they are plotted as a function of their actual $\alpha$ values, as calculated by the model from the measured temperature profile during treatment.

Overall, the validation points are in good agreement with the predictions. The results are particularly good for the chemicals compounds that can be measured using straightforward methods, such as acetic acid, monomeric sugars, and their degradation products. Chemical compounds that require more complex measurements are subjected to more bias, for 
example, OS. Additionally, the relatively low quantity of C6 OS produced by hydrolyses accentuates possible differences.

As the main achievement of this work, the combination of an original device able to continuously assess sample deformation during the process together with a DAEM approach allowed us to propose a predictive and validated model of chemical modification of poplar during hydrothermal treatment. Accounting for the similar structure of secondary cell wall, the method is likely to be valid also for other types of lignocellulosic biomass.

When biomass is used for bioethanol and chemicals production, the amounts of sugars and inhibition products released are extremely relevant parameters. The pretreatment step must maximize the sugar yield and the polysaccharides' accessibility for enzymatic hydrolysis while ensuring a low quantity of inhibitors. For example, from Figure 6, we can see that after 20 minutes of treatment at $180^{\circ} \mathrm{C}, \mathrm{OS}^{\prime}$ production is counterbalanced by their consumption. At the same time, furfural and HMF concentrations increase drastically. It means that intensifying the pretreatment severity would not be beneficial if a fermentation step is intended. On the contrary, if the aim is to obtain small molecules such as furfural, the treatment conditions should aim at high severity. The predictive approach of this work, namely the DEAM kinetics model together with expressions capable of predicting chemical alterations from the kinetics, is able to consider any time-temperature pathway. For example, in the case of simple plateautemperature treatments, it is able to build carpet plots to highlight the combined effects of temperature and residence time, as shown in the graphical abstract. Therefore, this approach is perfectly suited to assist the choice of the best treatment conditions, including under the constraints of the industrial pilot plant, such as the length of the heating phase or possible temperature overshoots due to the regulation. 


\section{Conclusions}

An original device for in-situ measurement of dimensional changes during hydrothermal treatment was developed and used for poplar. Shrinkage evolution was introduced as an indicator of the conversion degree to identify the parameters of a DAEM formulation. Physical and chemical characterizations served as a learning database to relay the chemical alterations to the conversion degree. The predictive potential of the model was then successfully tested using a validation database.

This predictive approach, validated for poplar but certainly applicable to other lignocellulosic biomasses, is capable of considering any time-temperature pathway, which assists in the choice of the best treatment compromise.

E-supplementary data of this work can be found in online version of the paper.

\section{Acknowledgments}

This study was carried out in the Centre Européen de Biotechnologie et de Bioéconomie (CEBB), supported by Région Grand Est, Département de la Marne, Greater Reims and the European Union. In particular, the authors would like to thank Département de la Marne, Greater Reims, Région Grand Est and European Union with European Regional Development Fund (ERDF Champagne Ardenne 2014-2020) for their financial support to the Chair of Biotechnology of CentraleSupélec. The authors would also like to acknowledge the French Council for Poplar as well as Huberlant sawmill (Cormicy, France) for providing the wood used in this study. 


\section{References}

Almeida, G., Brito, J.O., Perré, P., 2010. Alterations in energy properties of eucalyptus wood and bark subjected to torrefaction : The potential of mass loss as a synthetic indicator. Bioresour. Technol. 101, 9778-9784. https://doi.org/10.1016/j.biortech.2010.07.026

Almeida, G., Brito, J.O., Perré, P., 2009. Changes in wood-water relationship due to heat treatment assessed on micro-samples of three Eucalyptus species. Holzforschung 63, 8088. https://doi.org/10.1515/HF.2009.026

Anthony, D.B., Howard, J.B., 1976. Coal devolatilization and hydrogasification. AIChE J. 22, $625-656$.

Assor, C., Placet, V., Chabbert, B., Habrant, A., Lapierre, C., Pollet, B., Perré, P., 2009. Concomitant changes in viscoelastic properties and amorphous polymers during the hydrothermal treatment of hardwood and softwood. J. Agric. Food Chem. 57, 6830-6837. https://doi.org/10.1021/jf901373s

Baruah, J., Nath, B.K., Sharma, R., Kumar, S., Deka, R.C., Baruah, D.C., Kalita, E., 2018. Recent trends in the pretreatment of lignocellulosic biomass for value-added products. Front. Energy Res. 6, 1-19. https://doi.org/10.3389/fenrg.2018.00141

Cai, J., Liu, R., 2008. New distributed activation energy model: Numerical solution and application to pyrolysis kinetics of some types of biomass. Bioresour. Technol. 99, 27952799. https://doi.org/10.1016/j.biortech.2007.06.033

Cai, J., Wu, W., Liu, R., 2014. An overview of distributed activation energy model and its application in the pyrolysis of lignocellulosic biomass. Renew. Sustain. Energy Rev. 36, 236-246. https://doi.org/10.1016/j.rser.2014.04.052

Cavagnol, S., Roesler, J.F., Sanz, E., Nastoll, W., Lu, P., Perré, P., 2015. Exothermicity in wood 
torrefaction and its impact on product mass yields: From micro to pilot scale. Can. J.

Chem. Eng. 93, 331-339. https://doi.org/10.1002/cjce.22128

De Bhowmick, G., Sarmah, A.K., Sen, R., 2018. Lignocellulosic biorefinery as a model for sustainable development of biofuels and value added products. Bioresour. Technol. 247, 1144-1154. https://doi.org/10.1016/j.biortech.2017.09.163

Donohoe, B.S., Decker, S.R., Tucker, M.P., Himmel, M.E., Vinzant, T.B., 2008. Visualizing lignin coalescence and migration through maize cell walls following thermochemical pretreatment. Biotechnol. Bioeng. 101, 913-925. https://doi.org/10.1002/bit.21959

Engelund, E.T., Thygesen, L.G., Svensson, S., Hill, C.A.S., 2013. A critical discussion of the physics of wood-water interactions. Wood Sci. Technol. 47, 141-161. https://doi.org/10.1007/s00226-012-0514-7

Garrote, G., Dominguez, H., Parajo, J.C., 1999. Hydrothermal processing of lignocellulosic materials. Holz als Roh- und Werkst. 57, 191-202.

https://doi.org/10.1007/s001070050039

Gril, J., Thibaut, B., Berrada, E., Martin, G., 1993. Recouvrance hygrothermique du bois vert. I. Influence de la température. Cas du jujubier (Ziziphus lotus (L) Lam). Ann. des Sci. For. 50, 57-70. https://doi.org/10.1051/forest:19930104

Haghighi Mood, S., Hossein Golfeshan, A., Tabatabaei, M., Salehi Jouzani, G., Najafi, G.H., Gholami, M., Ardjmand, M., 2013. Lignocellulosic biomass to bioethanol, a comprehensive review with a focus on pretreatment. Renew. Sustain. Energy Rev. 27, 77-93. https://doi.org/10.1016/j.rser.2013.06.033

Hill, C.A.S., Norton, A., Newman, G., 2009. The water vapor sorption behavior of natural fibers. J. Appl. Polym. Sci. 112, 1524-1537. 
Hu, F., Jung, S., Ragauskas, A., 2012. Pseudo-lignin formation and its impact on enzymatic hydrolysis. Bioresour. Technol. 117, 7-12.

https://doi.org/10.1016/j.biortech.2012.04.037

Jullien, D., 1995. Analyse expérimentale et numérique des contraintes résiduelles dans un matériau élastique orthotrope élaboré par couches successives. Cas d'un disque de bois vert. Université Montpellier 2 - Sciences et techniques du Languedoc.

Lancha, J.P., Colin, J., Almeida, G., Perré, P., 2020. In situ measurements of viscoelastic properties of biomass during hydrothermal treatment to assess the kinetics of chemical alterations. Bioresour. Technol. 315, 123819. https://doi.org/10.1016/j.biortech.2020.123819

Lancha, J.P., Perré, P., Colin, J., Ruscassier, N., Lv, P., Almeida, G., 2021. Multiscale investigation on the chemical and anatomical changes of lignocellulosic biomass submitted to hydrothermal pre-treatment. Sci. Rep. 11, 1-16. https://doi.org/10.1038/s41598-02187928-y

Li, M.F., Chen, C.Z., Sun, R.C., 2014. Effect of pretreatment severity on the enzymatic hydrolysis of bamboo in hydrothermal deconstruction. Cellulose 21, 4105-4117. https://doi.org/10.1007/s10570-014-0451-8

Limayem, A., Ricke, S.C., 2012. Lignocellulosic biomass for bioethanol production: current perspectives, potential issues and future prospects. Prog. Energy Combust. Sci. 38, 449467. https://doi.org/10.1016/j.pecs.2012.03.002

Lin, Y., Chen, Z., Dai, M., Fang, S., Liao, Y., Yu, Z., Ma, X., 2018. Co-pyrolysis kinetics of sewage sludge and bagasse using multiple normal distributed activation energy model (MDAEM). Bioresour. Technol. 259, 173-180. 
https://doi.org/10.1016/j.biortech.2018.03.036

Liu, S., Lu, H., Hu, R., Shupe, A., Lin, L., Liang, B., 2012. A sustainable woody biomass biorefinery. Biotechnol. Adv. 30, 785-810.

https://doi.org/10.1016/j.biotechadv.2012.01.013

Liu, Z.H., Qin, L., Pang, F., Jin, M.J., Li, B.Z., Kang, Y., Dale, B.E., Yuan, Y.J., 2013. Effects of biomass particle size on steam explosion pretreatment performance for improving the enzyme digestibility of corn stover. Ind. Crops Prod. 44, 176-184.

https://doi.org/10.1016/j.indcrop.2012.11.009

Mankar, A.R., Pandey, A., Modak, A., Pant, K.K., 2021. Pretreatment of lignocellulosic biomass: A review on recent advances. Bioresour. Technol. 334, 125235.

https://doi.org/10.1016/j.biortech.2021.125235

Mihiretu, G.T., Chimphango, A.F., Görgens, J.F., 2019. Steam explosion pre-treatment of alkaliimpregnated lignocelluloses for hemicelluloses extraction and improved digestibility. Bioresour. Technol. 294, 122121. https://doi.org/10.1016/j.biortech.2019.122121

Mokdad, S.-A., Casalinho, J., Almeida, G., Perré, P., 2018. Assessment of biomass alterations during hydrothermal pretreatment by in- situ dynamic mechanical analysis. Biomass and Bioenergy 108, 330-337. https://doi.org/10.1016/j.biombioe.2017.11.014

Nitsos, C.K., Matis, K.A., Triantafyllidis, K.S., 2013. Optimization of hydrothermal pretreatment of lignocellulosic biomass in the bioethanol production process. ChemSusChem 6, 110122. https://doi.org/10.1002/cssc.201200546

Pachón-Morales, J., Colin, J., Pierre, F., Puel, F., Perré, P., 2019. Effect of torrefaction intensity on the flow properties of lignocellulosic biomass powders. Biomass and Bioenergy 120, 301-312. https://doi.org/10.1016/j.biombioe.2018.11.017 
Perré, P., Tian, Y., Lu, P., Malinowska, B., Bekri, J. El, Colin, J., 2021. A robust and frugal model of biomass pyrolysis in the range $100-800^{\circ} \mathrm{C}$ : Inverse analysis of DAEM parameters, validation on static tests and determination of heats of reaction. Fuel 288. https://doi.org/10.1016/j.fuel.2020.119692

Phuong, L.X., Takayama, M., Shida, S., Matsumoto, Y., Aoyagi, T., 2007. Determination of the accessible hydroxyl groups in heat-treated Styrax tonkinensis (Pierre) Craib ex Hartwich wood by hydrogen-deuterium exchange and2H NMR spectroscopy. Holzforschung 61, 488-491. https://doi.org/10.1515/HF.2007.086

Pitt, G.J., 1962. The kinetic of the evolution of volatile products from coal. Fuel 41, 267-274.

Placet, V., Perré, P., 2006. Chambre d'essai bi-climatique. Ref: BFF 06P0432. Ref: BFF 06P0432.

Salmén, L., 1990. Thermal Expansion of Water-saturated Wood. Holzforschung 44, 17-20. https://doi.org/10.1515/hfsg.1990.44.1.17

Shinde, S.D., Meng, X., Kumar, R., Ragauskas, A.J., 2018. Recent advances in understanding the pseudo-lignin formation in a lignocellulosic biorefinery. Green Chem. 20, 2192-2205. https://doi.org/10.1039/c8gc00353j

Siau, J.F., 1984. Transport Processes in Wood, Springer Series in Wood Science. Springer Berlin Heidelberg, Berlin, Heidelberg. https://doi.org/10.1007/978-3-642-69213-0

Sluiter, A., Hames, B., Ruiz, R., Scarlata, C., Sluiter, J., Templeton, D., 2008a. Determination of sugars, byproducts, and degradation products in liquid fraction process samples, National Renewable Energy Laboratory. https://doi.org/NREL/TP-510-42623

Sluiter, A., Hames, B., Ruiz, R., Scarlata, C., Sluiter, J., Templeton, D., Nrel, D.C., 2011. Determination of Structural Carbohydrates and Lignin in Biomass Determination of Structural Carbohydrates and Lignin in Biomass. Golden. 
Sluiter, A., Ruiz, A., Scarlata, C., Sluiter, J., Templeton, D., 2008b. Determination of Extractives in Biomass, Technical Report NREL/TP-510-42619. https://doi.org/NREL/TP-510-42621

Sui, W., Chen, H., 2016. Effects of water states on steam explosion of lignocellulosic biomass. Bioresour. Technol. 199, 155-163. https://doi.org/10.1016/j.biortech.2015.09.001

Sui, W., Chen, H., 2015. Water transfer in steam explosion process of corn stalk. Ind. Crops Prod. 76, 977-986. https://doi.org/10.1016/j.indcrop.2015.08.001

Sujan, K.C., Yamamoto, H., Matsuo, M., Yoshida, M., Naito, K., Shirai, T., 2015. Continuum contraction of tension wood fiber induced by repetitive hygrothermal treatment. Wood Sci. Technol. 49, 1157-1169. https://doi.org/10.1007/s00226-015-0762-4

Tian, Y., Perré, P., 2021. Multiple-distribution DAEM modelling of spruce pyrolysis: An investigation of the best trade-off regarding the number and shape of distributions. Energy Convers. Manag. 229. https://doi.org/10.1016/j.enconman.2020.113756

Ueda Matsuo, M., Niimi, G., Sujan, K.C., Yoshida, M., Yamamoto, H., 2016. Hygrothermal recovery of compression wood in relation to elastic growth stress and its physicochemical characteristics. J. Mater. Sci. 51, 7956-7965. https://doi.org/10.1007/s10853-016-0065-7

Vallejos, M.E., Felissia, F.E., Area, M.C., 2017. Hydrothermal Treatments Applied to Agro-and Forest- Industrial Waste to Produce High Added-Value Compounds. BioResources 12, 2058-2080.

Vand, V., 1943. A theory of the irreversible electrical resistance changes of metallic films evaporated in vacuum. Proc. Phys. Soc. 55, 222-246. https://doi.org/10.1088/0959$5309 / 55 / 3 / 308$

Vila, C., Francisco, J.L., Santos, V., Parajó, J.C., 2013. Effects of hydrothermal processing on the cellulosic fraction of Eucalyptus globulus wood. Holzforschung 67, 33-40. 
https://doi.org/10.1515/hf-2012-0046

Wang, C., Li, H., Li, M., Bian, J., Sun, R., 2017. Revealing the structure and distribution changes of Eucalyptus lignin during the hydrothermal and alkaline pretreatments. Sci. Rep. 7, 110. https://doi.org/10.1038/s41598-017-00711-w

Ximenes, E., Farinas, C.S., Kim, Y., Ladisch, M.R., 2017. Hydrothermal Pretreatment of Lignocellulosic Biomass for Bioethanol Production, in: Ruiz, H., Hedegaard Thomsen, M., Trajano, H. (Eds.), Hydrothermal Processing in Biorefineries. Springer, Cham, pp. 181205. https://doi.org/10.1007/978-3-319-56457-9

Yin, Y., Berglund, L., Salmén, L., 2011. Effect of steam treatment on the properties of wood cell walls. Biomacromolecules 12, 194-202. https://doi.org/https://doi.org/10.1021/bm101144m

\section{Figure captions}

Figure 1. Flow chart of analysis. Fractions in blue were analyzed for monosaccharides, oligosaccharides, organic acids, and degradation products, and fractions in red were analyzed for isotherm sorption.

Figure 2. Up to scale CAD (Computer Aided Design) model of the device. Left: (a) instrumentation zone; (b) reaction chamber; (c) actuator ( $3 \mu \mathrm{m}$ precision); (d) load cell (10-5 N precision); (e) frame for zoom; (f) compression rod; (g) sample; (h) sample holder; (i) electric heater; (j) liquid water. Zoom in the device (right): 1 - fin set (4 on each zone - cold/hot); 2 controlled leakage (3 symmetric outlets); 3 - compression rod. Adapted from (Lancha et al., 2020). 
Figure 3. Radial shrinkage (\%) of biomass samples subjected to hydrothermal treatment: experimental points and the corresponding DAEM model. These results reflect the irreversible component exclusively due to chemical degradation.

Figure 4. (a) Mass loss (3 repetitions) for different durations of hydrothermal treatment at 160 ${ }^{\circ} \mathrm{C}$ and $180^{\circ} \mathrm{C}$. (b) Sorption/desorption curves at $25^{\circ} \mathrm{C}$ for native and treated poplar biomass, (c) $\mathrm{pH}$ evolution at $160^{\circ} \mathrm{C}$ and $180^{\circ} \mathrm{C}$, and (d) acetic acid content of the liquid fraction.

Figure 5. Effect of residence time on the content of sugars and their respective degradation products in the liquid phase at $160^{\circ} \mathrm{C}$ and $180^{\circ} \mathrm{C}$. Top) $\mathrm{C} 5$ sugars and bottom) $\mathrm{C} 6$ sugars.

Figure 6. Biomass properties as a function of the degree of conversion $(\alpha)$. 


\section{Tables and Figures}

Figure 1:

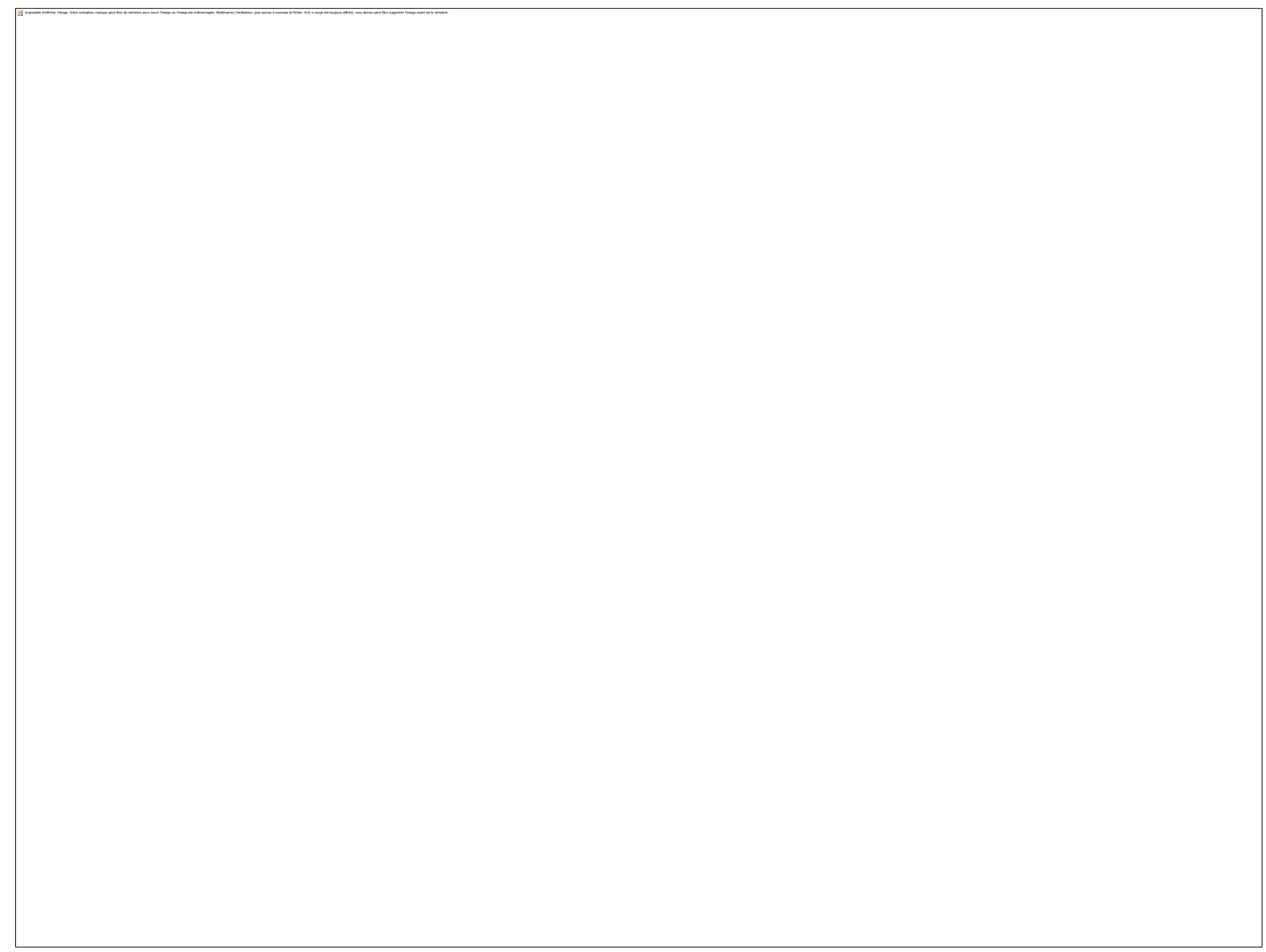

Figure 1. Flow chart of analysis. Fractions in blue were analyzed for monosaccharides, oligosaccharides, organic acids, and degradation products, and fractions in red were analyzed for isotherm sorption. 
Figure 2:

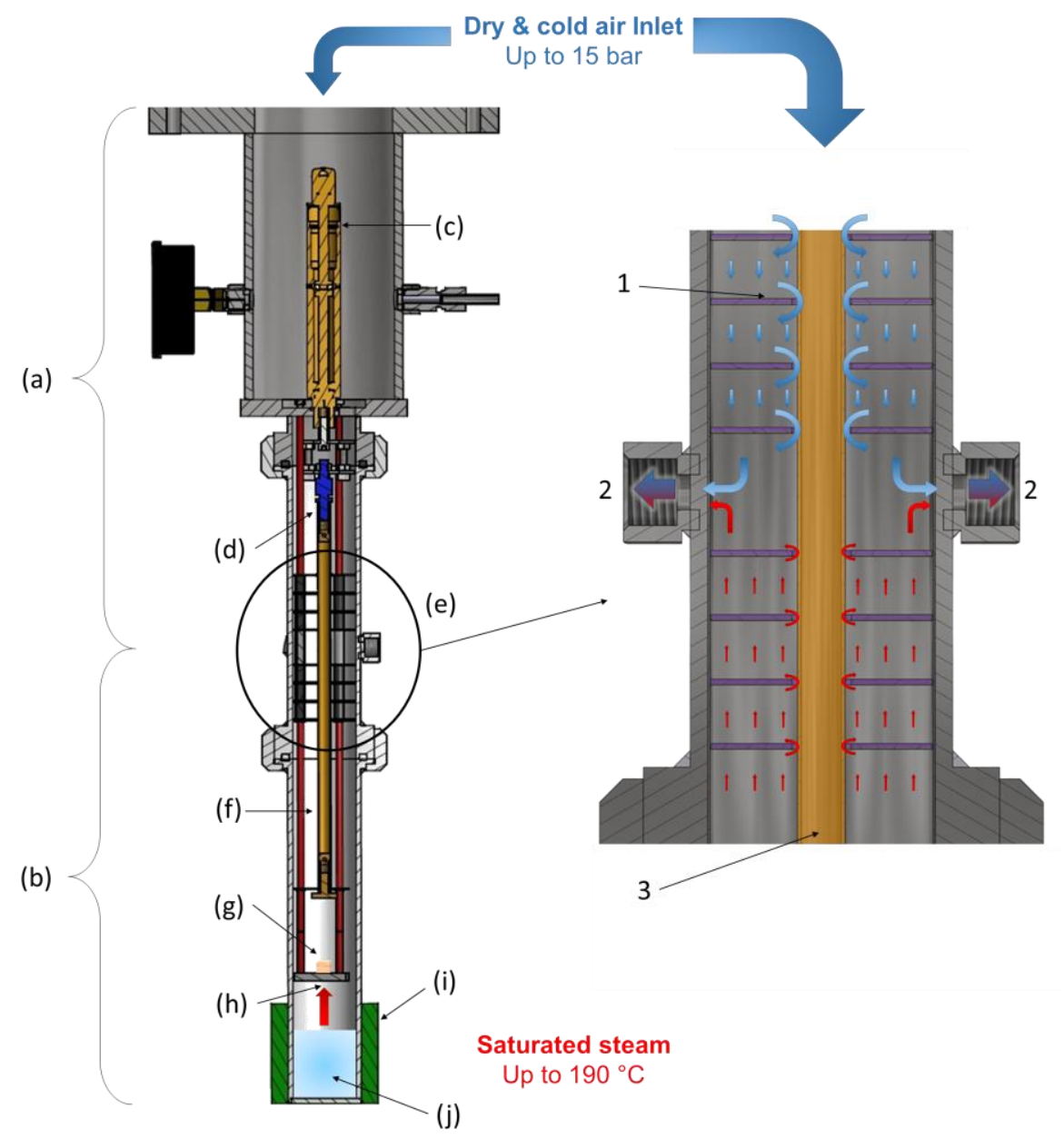

Figure 2. Up to scale CAD (Computer Aided Design) model of the device. Left: (a)

instrumentation zone; (b) reaction chamber; (c) actuator (3 $\mu \mathrm{m}$ precision); (d) load cell (10-5 N precision); (e) frame for zoom; (f) compression rod; (g) sample; (h) sample holder; (i) electric heater; (j) liquid water. Zoom in the device (right): 1 - fin set (4 on each zone - cold/hot); 2 controlled leakage (3 symmetric outlets); 3 - compression rod. Adapted from (Lancha et al., 2020). 
Figure 3:

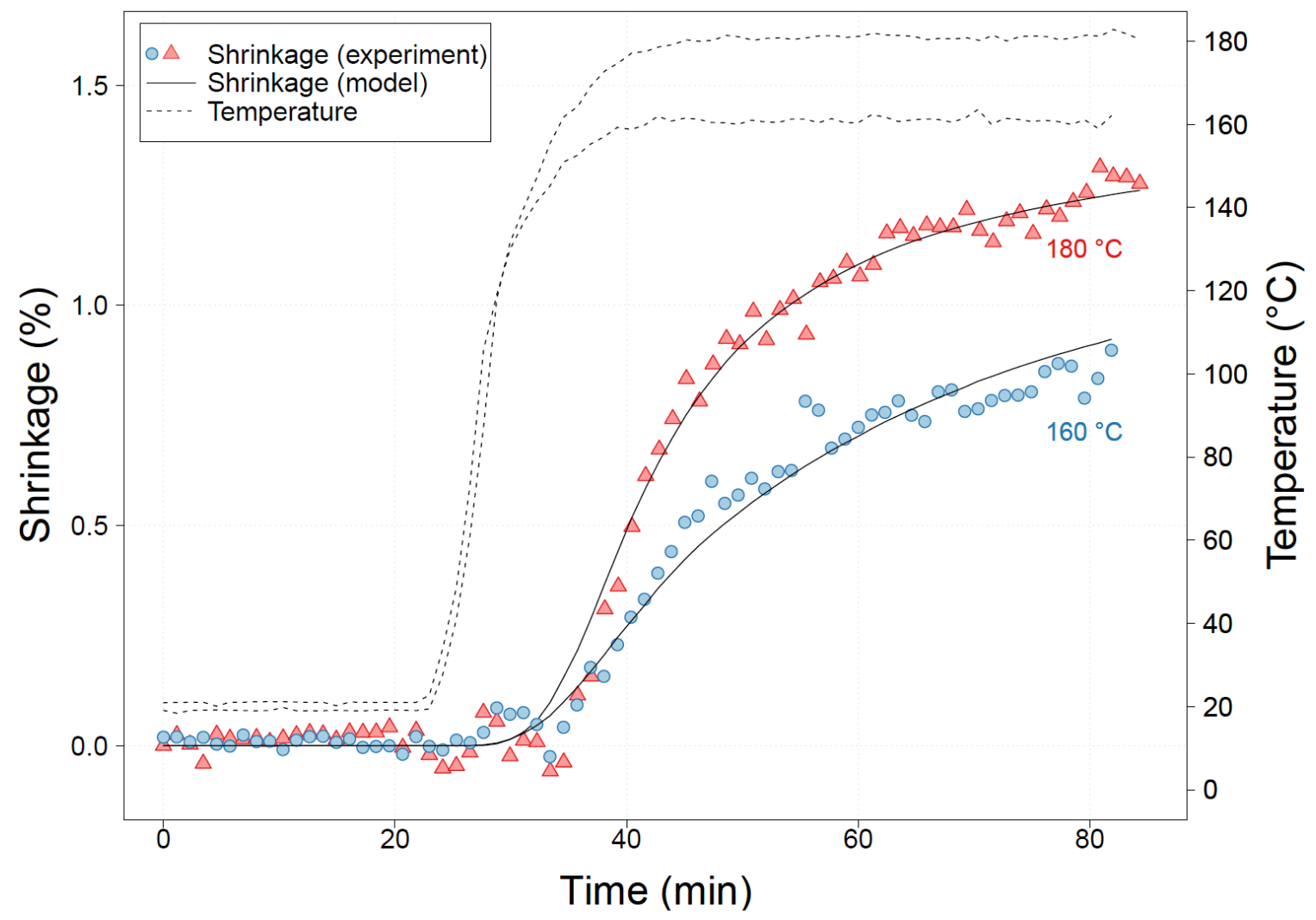

Figure 3. Radial shrinkage (\%) of biomass samples subjected to hydrothermal treatment:

experimental points and the corresponding DAEM model. These results reflect the irreversible component exclusively due to chemical degradation. 
Figure 4:
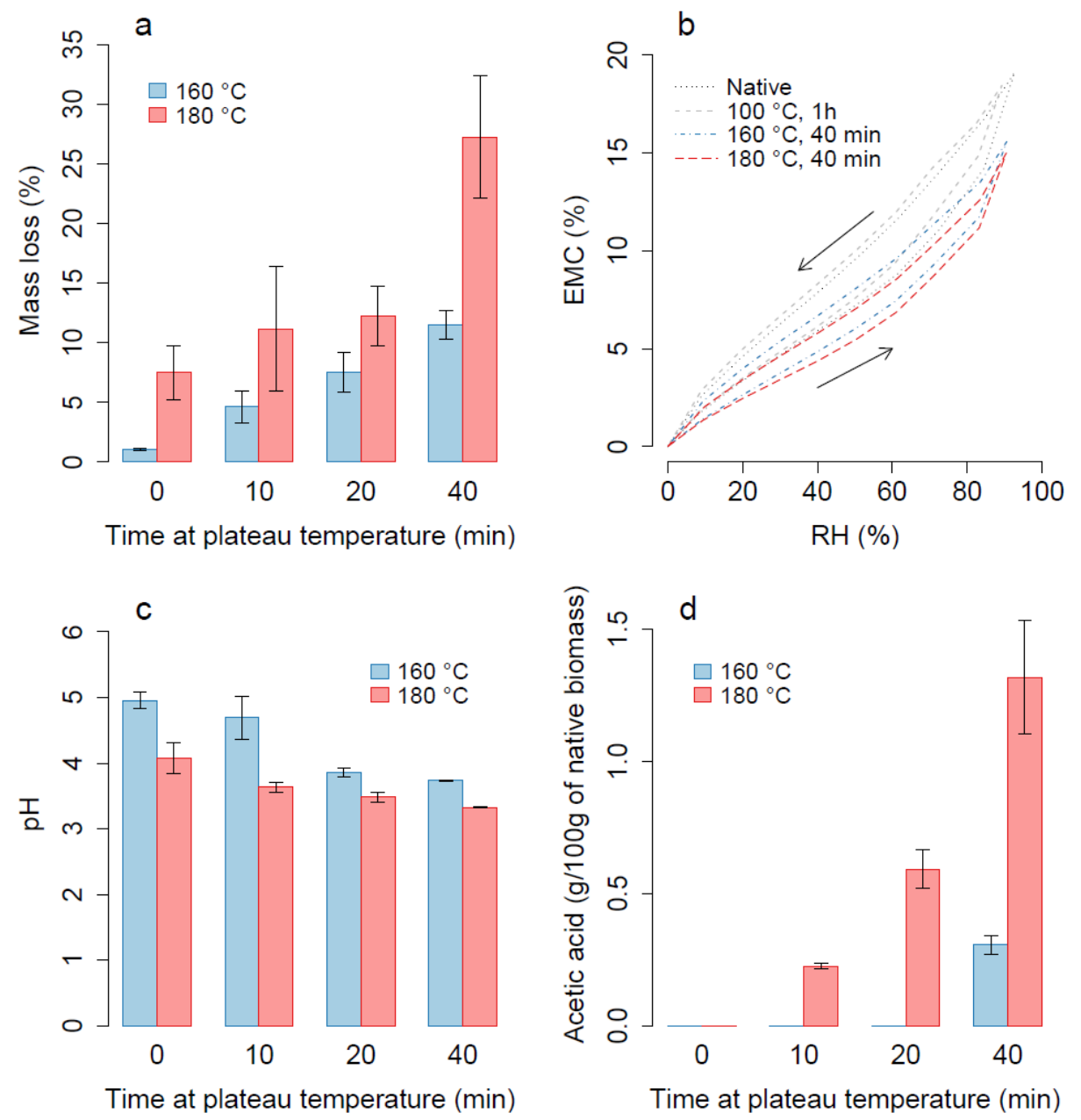

Figure 4. (a) Mass loss ( 3 repetitions) for different durations of hydrothermal treatment at $160^{\circ} \mathrm{C}$ and $180^{\circ} \mathrm{C}$. (b) Sorption/desorption curves at $25^{\circ} \mathrm{C}$ for native and treated poplar biomass, (c) pH evolution at $160^{\circ} \mathrm{C}$ and $180^{\circ} \mathrm{C}$, and (d) acetic acid content of the liquid fraction. 
Figure 5:
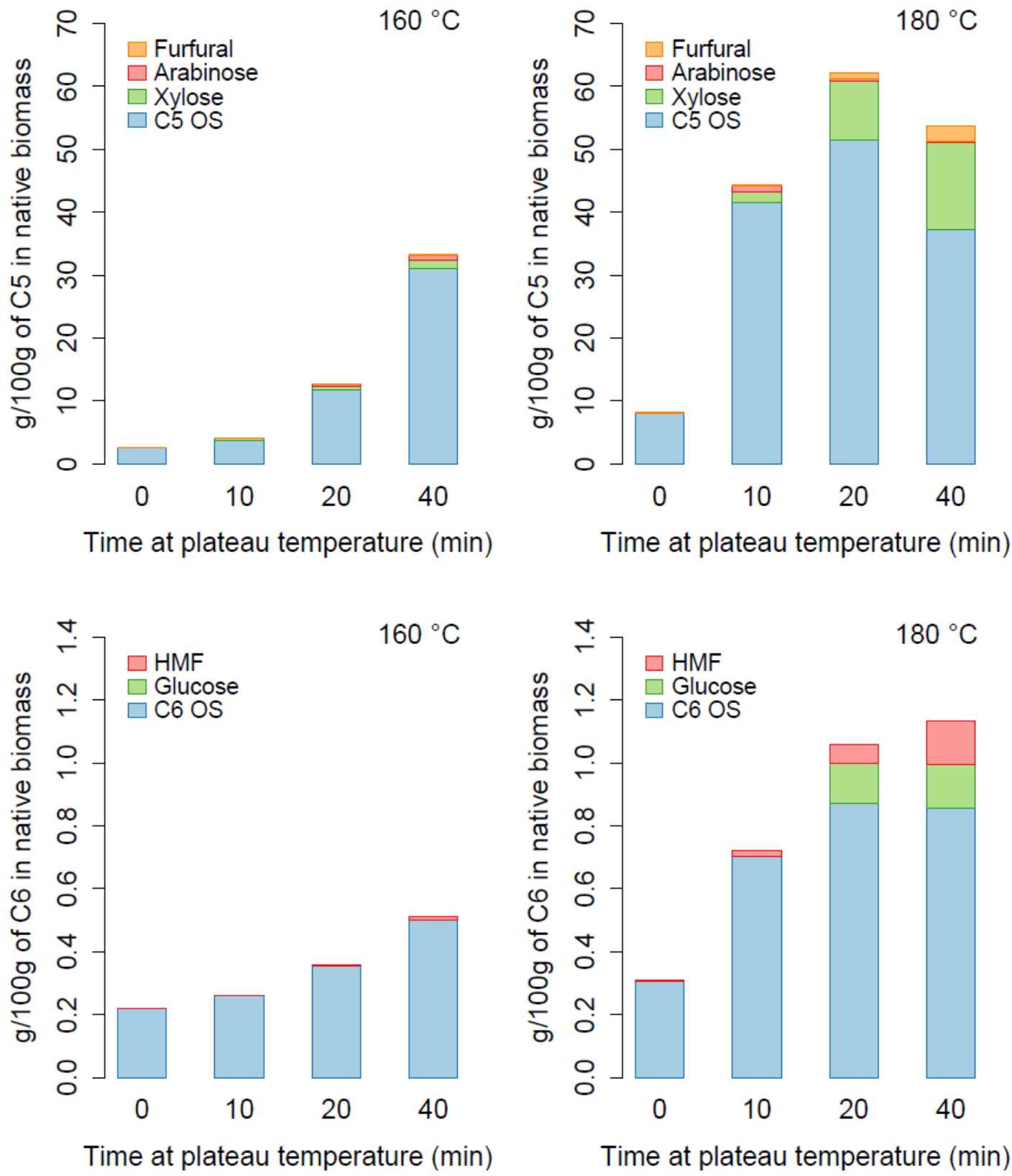

Figure 5. Effect of residence time on the content of sugars and their respective degradation products in the liquid phase at $160^{\circ} \mathrm{C}$ and $180^{\circ} \mathrm{C}$. Top) $\mathrm{C} 5$ sugars and bottom) $\mathrm{C} 6$ sugars. 
Figure 6:
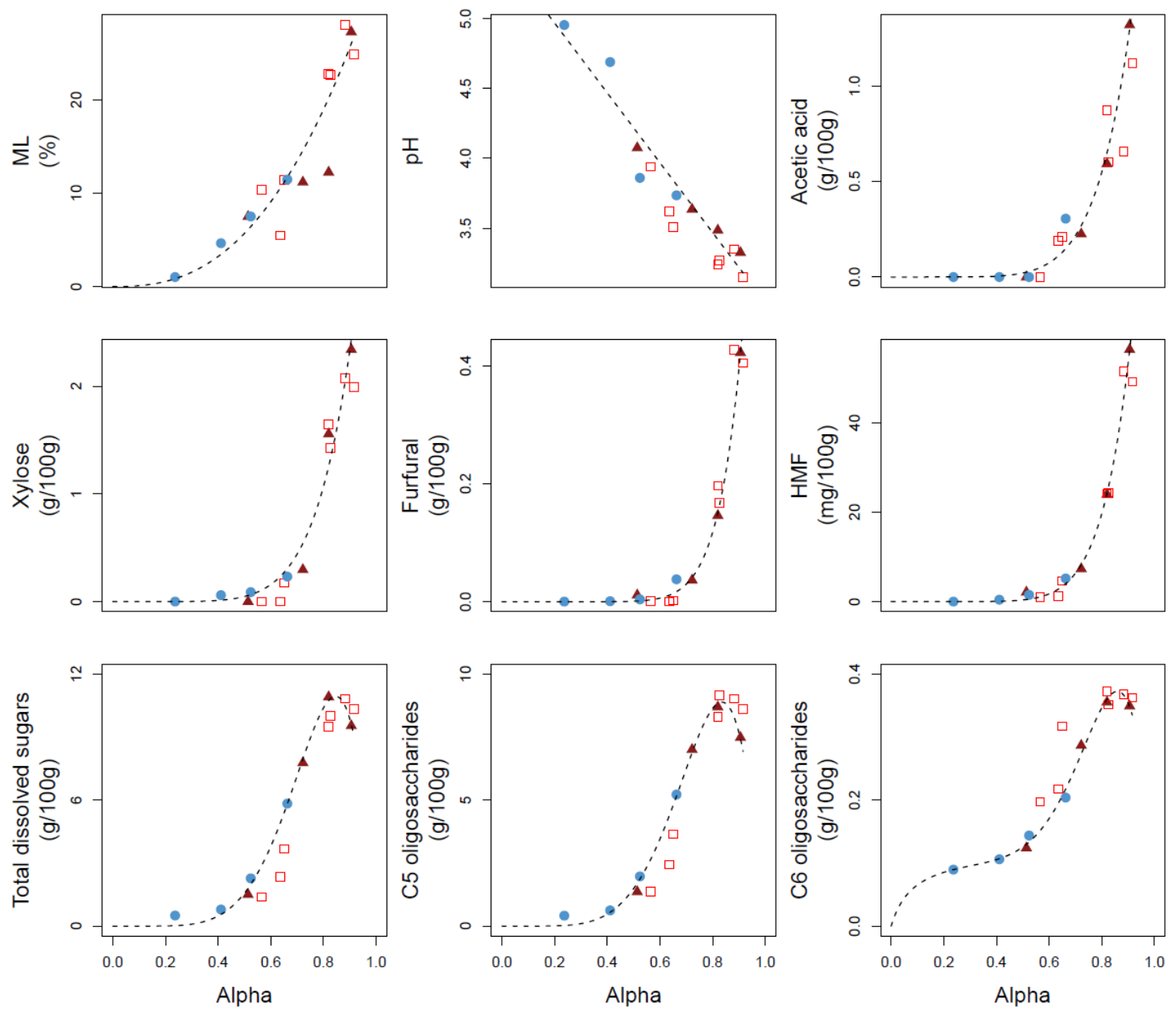

- $160{ }^{\circ} \mathrm{C} \triangle 180^{\circ} \mathrm{C} \quad \square \quad$ Validation-.-- Models

Figure 6. Biomass properties as a function of the degree of conversion $(\alpha)$. 
Table 1. Expressions proposed to express biomass characteristics as a function of the degree of conversion $(\alpha)$ caused by hydrothermal treatment

$\mathrm{ML}$

(\%)

$$
M L=33.47 \alpha^{2.56}
$$

$\mathrm{pH}$

$$
p H=5.46-2.50 \alpha
$$

\begin{tabular}{ll}
\hline Acetic acid (AA) & $A A=2.58 \alpha^{6.94}$ \\
(g/100g of native biomass) & $X Y L=4.69 \alpha^{6.63}$ \\
\hline Xylose (XYL) & $F U R=1.16 \alpha^{10.26}$ \\
(g/100g of native biomass) & \\
\hline Furfural (FUR) & $H M F=129.91 \alpha^{8.46}$ \\
(g/100g of native biomass) & \\
\hline HMF & $T D S=256.1 \alpha^{6.22}(1-\alpha)^{1.13}$ \\
(mg/100g of native biomass) & \\
\hline Total dissolved sugars (TRS) & \\
(g/100g of native biomass) & $C 5 O S=232.7 \alpha^{6.08}(1-\alpha)^{1.20}$ \\
\hline C5 oligosaccharides (C5OS) & \\
(g/100g of native biomass) & $C 60 S=\frac{0.12 \alpha}{(0.09+\alpha)}+9.37 \alpha^{7.54}(1-\alpha)^{1.24}$ \\
\hline C6 oligosaccharides (C6OS) & \\
(g/100g of native biomass) & \\
\hline
\end{tabular}

